\title{
ENFERMAGEM
}

\section{CÂNCER DO COLO DO ÚTERO: PAPEL DO ENFERMEIRO NA ESTRATÉGIA E SAÚDE DA FAMÍLIA}

\author{
DOI: http://dx.doi.org/10.31072/rcf.v9i1.517 \\ CERVICAL CANCER: ROLE OF THE NURSE IN THE STRATEGY AND FAMILY HEALTH \\ Bruna Leticia Silveira'; Rafaela Cristina Bandeira Maia²; Mariana Ferreira Alves de \\ Carvalho ${ }^{3}$.
}

RESUMO: O Câncer Cervical é considerado atualmente um importante problema de saúde pública, não apenas no Brasil, como no mundo. O mesmo tem sido responsável por cerca de $10 \%$ dos casos de câncer na população feminina, o que tem gerado ao ano aproximadamente 500 mil casos novos, que pode ser traduzido em 02 mortes por minuto. Frente a este contexto, surge como ferramenta indispensável do cuidar, o papel do profissional de Enfermagem na Estratégia e Saúde da Família (ESF), setor primário de atenção à saúde, o qual atua principalmente com promoção e prevenção das patologias, dando ênfase a Saúde da Mulher. Este estudo objetivou descrever por meio de uma revisão de literatura, o valor do exame Papanicolau na prevenção do câncer do colo do útero, com foco na atuação da equipe de enfermagem na ESF. A pesquisa foi realizada por meio de uma sistemática revisão de literatura, as estratégias de busca foram às bases de dados: Biblioteca Virtual em Saúde (BVS), Scientific Eletronic Library Online (SciELO), Manuais do Ministério da Saúde e acervo da Biblioteca Júlio Bordignon da Faculdade de Educação e Meio Ambiente- FAEMA. Por meio da leitura e análise dos artigos, percebeu-se que é de suma importância o exame Papanicolau para o diagnóstico precoce da doença e concomitante, redução de danos à saúde da mulher, bem como, a efetiva atuação do enfermeiro dentro da ESF, uma vez que este possui formação mais generalista, com focos em humanização e educação em saúde, o que pode contribuir de maneira significativa para o enfrentamento do câncer de colo uterino.

Descritores (DeCS): Enfermagem. Colo do útero. Neoplasias. Papanicolau. Prevenção.

\begin{abstract}
Cervical cancer is considered an important public health problem today, not only in Brazil, but also in the entire world. This has been responsible for approximately $10 \%$ of cancer cases within the female population, which has generated approximately 500 thousand new cases per year, which can be translated into 02 deaths per minute. Looking at this context,
\end{abstract}

\footnotetext{
1 Bacharel em Enfermagem pela Faculdade de Educação e Meio Ambiente - FAEMA. E-mail: brunaletycya@hotmail.com. ORCID: https://orcid.org/0000-0001-7788-7269;

2 Pós Graduação em andamento em Gestão e Logística Hospitalar pela Universidade Cândido Mendes, R.J. Brasil. Bacharel em Enfermagem pela Faculdade de Educação e Meio Ambiente - FAEMA. E-mail: rafaela_maia.2012@hotmail.com. ORCID: https://orcid.org/0000-0003-1189-5391;

${ }^{3}$ Mestre em Teologia, pela Faculdades EST. Especialista em Especialização Multiprofissional em Saúde da Família pela Universidade Federal de Goiás - UFG. Especialista em Enfermagem em Obstetrícia pela Pontifícia Universidade Católica de Goiás - PUC GOIÁS, Brasil. Graduação pelo em Enfermagem. Centro Universitário de Anápolis, UNIEVANGÉLICA. E-mail: marianaferreira_9@hotmail.com. ORCID: https://orcid.org/0000-0003-38110339.
} 
the role of a nursing professional in the Family health and strategy (FHS), the primary health care sector, is an indispensable tool for caring, working mainly with promotion and prevention of pathologies, emphasizing at the moment the health of women. This scientific study aimed to describe, through a review of the literature, the importance of the pap smear in the prevention of cervical cancer, focusing on the performance of the nursing team in the FHS. The research was carried out through a systematic review of the literature, the search strategies were the data to the databases: Virtual Health Library (VHL), Scientific Electronic Library Online (SciELO), Manuals of the Ministry of Health and library of Júlio Bordignon, Library of the College of Education and Environment - FAEMA. Through the reading and analysis of the articles, it was noticed that the pap smear of early diagnosis of the disease and concomitant, reduction of the damage to the woman's health, as well as the effective performance of nurses within the FHS once he or she has a more general training, with focus on humanization and health education, which can contribute significantly to the fight against cervical cancer.

Descriptors: Nursing. Uterine cervix. Neoplasms. Papanicola. Prevention.

\section{INTRODUÇÃO}

O Câncer do Colo do Útero vem sendo responsável por aproximadamente $10 \%$ dos casos de cânceres na população feminina no mundo, este por sua vez, tem gerado aproximadamente 500 mil casos novos ao ano, o que por sua vez, pode ser traduzido em duas mortes por minuto ${ }^{(1)}$. É tido no Brasil como um problema de saúde pública, sendo que as maiores taxas de prevalência e mortalidade da doença têm sido encontradas em mulheres que possuem baixa condição socioeconômica. (2)

Segundo Arruda et al. (3), é citada como a segunda neoplasia mais prevalente nas mulheres, sendo também, a segunda maior causadora de mortes nesse público no Brasil, sendo superada apenas pela neoplasia da mama. Esses números alarmantes de mortalidade estão diretamente relacionados ao diagnóstico tardio da doença, o qual, pode está relacionado aos mais diversos fatores, podendo citar: dificuldade de acesso da população aos serviços de prevenção e dificuldades dos gestores em estabelecer ações que envolvam os vários níveis de atenção, integrando promoção, prevenção, diagnóstico e tratamento. ${ }^{(1)}$

O câncer cervical desenvolve-se através de uma lesão que antecede o epitélio na junção escamo-colunar e está ligado a diversos fatores de risco, como por exemplo: infecção por Papiloma Vírus Humano (HPV), tabagismo, condições socioeconômicas, sistema imunosuprimido, atividades sexuais de início precoce dentre diversos outros. (4)

Um dos principais meios de identificar uma lesão no colo do útero é através do exame de preventivo, denominado Papanicolau. No entanto, muitas mulheres deixam de fazê-lo por medo, vergonha, falta 
de informação e algumas vezes, até por falta de confiança no profissional de saúde, deixando evidente, a necessidade de maior compreensão do profissional enfermeiro, sobre sua atuação nesse contexto. ${ }^{(5)}$

Frente ao exposto, o Papanicolau é uma importante ferramenta do cuidar e simultaneamente do prevenir, faz-se indispensável mencionar a Atenção Básica a Saúde (ABS), a qual corresponde ao nível de assistência primária a saúde, responsável pela promoção e prevenção. Esta, por sua vez, desenvolve suas atividades por meio da Estratégia e Saúde da Família (ESF), programa este, que visa à reorganização da assistência em saúde, trabalha a família como centro da atenção, e não mais o doente, de modo a agir preventivamente sobre essa população.

Considerando que o melhor método para redução de índices de morbimortalidade da doença, está basicamente, em atitudes preventivas, torna-se de suma importância a atuação deste setor, especialmente, com elaboração de estratégias que visem o alcance da população. ${ }^{(6)}$

O diagnóstico precoce da doença temse a possibilidade de obter um tratamento adequado e com danos de menor amplitude ao cliente, o qual pode chegar em até $100 \%$ de expectativa de cura. ${ }^{(7)}$
Justifica-se a importância desta pesquisa, ao destacar a necessidade do profissional enfermeiro em traçar melhores estratégias junto a sua equipe, para alcançar o público alvo específico, de modo a conseguir demonstrar a importância do exame preventivo Papanicolau e assim, favorecer a redução dos índices de morbimortalidade da doença.

\section{METODOLOGIA}

O presente estudo, trata-se de uma revisão de literatura atual, que foi realizada por meio de revisão sistemática de artigos indexados e publicados em base de dados da Biblioteca Virtual da Saúde (BVS), que compreende a SciELO (Scientific Eletronic Library Online), Biblioteca de Saúde Pública - Fundação Oswaldo Cruz (FIOCRUZ), Acervo da OPAS (Organização Pan-Americana de Saúde), Sistema de Informação da OMS (Organização Mundial de Saúde), LILACS (Literatura Latino-Americana e do Caribe em Ciências da Saúde), MEDLINE (Literatura Internacional em Ciências da Saúde), Manuais de normas técnicas do Ministério da Saúde e Ministério das Cidades, o acervo da biblioteca Júlio Bordignon também foi utilizado para a construção desta pesquisa.

A delimitação temporal de 2.000 à 2.016, porém, houve utilização de publicações relevantes consideradas 
antigas, como o livro, "Anatomia e Fisiologia Humana" de KAWAMOTO, publicado em 1988.

Os materiais foram analisados de acordo com os critérios que inclusão: material publicado em bases de dados confiáveis, disponíveis em língua portuguesa, espanhola ou inglesa e que possuíam relevância com a temática proposta.

Sendo os critérios de exclusão: os materiais que não tivessem conexão a com temática do estudo, que não pertencesse a uma base de dados confiável ou ainda que não pertencessem aos idiomas de português, espanhol ou inglês.

Foram usados os seguintes descritores em base DeCS (Descritores em Ciências da Saúde):

- Neoplasias do Colo do Útero; Prevenção Primária; Promoção da Saúde; e Papel do Profissional de Enfermagem.

Durante a busca, foram pesquisadas e encontradas 70 ferramentas de estudo, destas, utilizou-se 48, por estarem de acordo com os critérios de inclusão.

Destes, 12 (25\%) eram artigos científicos, $02(4,17 \%)$ teses e trabalhos de conclusão de curso, 21 (43,75\%) periódicos divulgados em revistas eletrônicas, 01 $(2,1 \%)$ diretriz, 01 era lei $(2,1 \%), 07$ $(14,58 \%)$ eram livros, 01 (2,1\%) protocolo, $01(2,1 \%)$ Informe Técnico, 01 (2,1\%) resolução e 01 (2,1\%) manual do Ministério da Saúde ou do Ministério das Cidades.

\section{REVISÃO DE LITERATURA}

\subsection{Anatomia do sistema reprodutor feminino}

O organismo humano é formado por diversos órgãos e estruturas que são interrelacionados e interdependentes, ou seja, estruturas com características peculiares, porém com funções distintas que se completam, sendo todas indispensáveis para o bom funcionamento orgânico e fisiológico. ${ }^{(8)}$

As estruturas orgânicas que formam o sistema reprodutor feminino possuem responsabilidade primordial sob a reprodução, sendo eles a vulva, vagina, útero, ovários, trompas e mamas. ${ }^{(9)}$

As principais funções deste sistema de acordo com Brunner e Suddarth ${ }^{(10)}$ são as de "produzir óvulos, secretar hormônios, nutrir e proteger o desenvolvimento do bebê durante os nove meses de gestação".

A vagina é o órgão de cópula feminino e atua juntamente com a cavidade uterina como canal para o parto. Já a vulva, também denominada como conjunto pudendo feminino constitui órgãos genitais externos, que contribuem para a cópula entre homem e mulher. (11)

De acordo com definições de Brunner e Suddarth (10), "a genitália externa (a vulva) 
inclui duas pregas teciduais espessas, chamadas de grandes lábios, e dois lábios menores de tecido delicado, denominados pequenos lábios", entre estes lábios, na porção superior, está localizado o clitóris, que é basicamente uma estrutura orgânica extremamente sensível e designada a fornecer sensação de prazer para a mulher durante $o$ ato sexual, abaixo e também entre os lábios, está o meato urinário, orifício responsável pela passagem da urina. Abaixo deste orifício, encontra-se outro orifício de tamanho maior, denominado intróito vaginal e está destinado para a penetração do pênis durante $o$ ato sexual.

O útero constitui um órgão interno do aparelho reprodutivo feminino, o qual possui aspecto similar ao de uma pêra, tendo como função primordial, o fornecimento de um ambiente seguro e nutritivo para o bebê durante o período gestacional. Ou seja, funciona como abrigo para a nova vida que se formará. (12)

Está localizado no abdome, mais precisamente na porção inferior, sobre a vagina, entre a bexiga e o reto. Possui variabilidade de tamanho de acordo com idade da mulher, tamanho, estado hormonal e ainda paridade (13). Em sua maioria, apresenta-se com " $8 \mathrm{~cm}$ de comprimento, $5 \mathrm{~cm}$ de largura e 2 a $3 \mathrm{~cm}$ de espessura". (14)
O útero apresenta-se dividido em duas partes distintas, sendo eles o colo e o corpo. O colo está localizado no alto da vagina e o corpo, é a parte responsável por dar origem ao processo menstrual (8). A Figura 1 apresenta a anatomia do colo uterino:

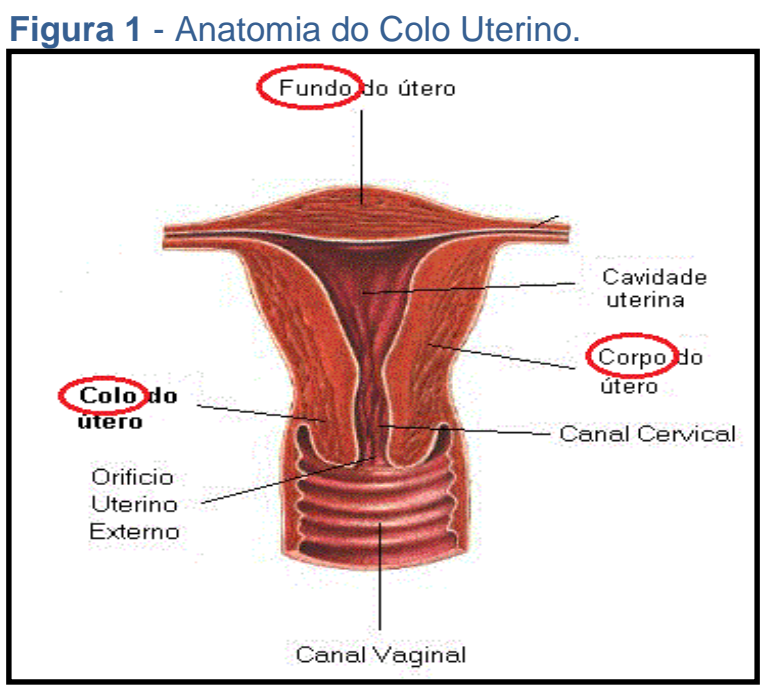

Fonte: Adaptado de SAÚDE\&VIDA (2002).

As tubas uterinas, também chamadas de Trompas de Falópio, além de constituírem o local da fecundação, também possuem a responsabilidade de conduzir a célula fecundada até o útero, atividade esta possível, devido às trompas, ligarem o útero aos ovários, vale mencionar, que o processo de condução desta célula, é realizado por meio de movimentos peristálticos e ciliares. ${ }^{(8)}$

Os ovários são responsáveis pela síntese de células germinativas femininas, a citar o óvulo e hormônios como a progesterona e o estrogênio, responsáveis 
pelo desenvolvimento das características sexuais. Também possuem importante papel sobre o útero, auxiliando em mecanismos de implantação do óvulo e no inicio do desenvolvimento do embrião. $O$ sistema reprodutor feminino funciona em conjunto com o sistema reprodutor masculino, de modo a garantir a continuidade da espécie. Atuam por meio de produção de células germinativas e mecanismos fisiológicos que garantem a fusão destas dentro do corpo da mulher. (11)

As mamas também são estruturas orgânicas consideradas partes constituintes do sistema reprodutor feminino, estão localizadas entre a $2^{\underline{a}}$ e a $6^{\underline{a}}$ costela, mais precisamente sobre 0 músculo peitoral, segue desde o externo até as axilas, cada mama possui de 12 a 20 lobos sob a forma de cone, os quais são formados de elementos glandulares, sendo separado por tecido adiposo e tecido fibroso, o que mantêm os lobos juntos. (10)

De acordo com o autor já citado, durante o período gravídico e de lactação ocorre produção de leite nos lóbulos e em seguida estes são carregados através dos ductos até o mamilo, o primeiro leite materno é denominado colostro e por meio deste a mãe ainda transfere anticorpos para o Recém-Nascido ( $R N)$, o que fortalece a tese da importância do aleitamento materno.

\subsection{Câncer em seus aspectos gerais}

A palavra câncer deriva do grego karkínos e em seu sentido real, significa caranguejo, foi utilizado pela primeira vez por Hipócrates, o chamado pai da medicina. Atualmente refere-se a um conjunto de mais de 100 doenças caracterizadas por crescimento celular desordenado. ${ }^{(15)}$

De acordo com Almeida (16) utilizou-se tal termo, devido à capacidade da doença de se proliferar de modo infiltrante, assimilando-se deste modo, a características do caranguejo, ao considerar principalmente a capacidade deste crustáceo, de infiltrar suas pernas na areia, dificultando assim a sua remoção.

O câncer é tido como uma das doenças mais temidas pela população em geral, tal fato dá-se devido à cultura de morte, sofrimento e de dor que se criou sobre tal temática. É considerado como importante problema de saúde pública, principalmente em países desenvolvidos ou que estejam em desenvolvimento, considerando a maior incidência neste cenário. ${ }^{(16)}$

Ressalta-se que são anualmente identificados no mundo, cerca de 10 milhões de novos casos desta doença, sendo que a mesma possui responsabilidade de aproximadamente $12 \%$ das mortes em geral (17). É considerada por uma pesquisa realizada 
pela Organização Mundial de Saúde (OMS), a terceira causa de morte entre as pessoas no mundo, sendo a segunda maior causa de morte no Brasil em 2012. (16)

Estima-se que, para o ano 2030, pode-se esperar um número de 27 milhões de casos incidentes de câncer, bem como, 17 milhões de mortes por câncer e ainda, 75 milhões de pessoas vivas, portadoras da doença. ${ }^{(18)}$

Vale frisar que, o organismo humano, possui mecanismos próprios de crescimento e renovação celular, sendo deste modo, normal a multiplicação e crescimento destas, no corpo do indivíduo. Porém, para que haja controle no número de células no organismo, e não haja deste modo, um número elevado das mesmas, também é comum que, o próprio organismo, faça o controle do tempo de vida dessas células, ou seja, para que, seja possível a renovação dessas células, existem simultaneamente, nascimento e desenvolvimento de células novas e a morte (apoptose), de células consideradas velhas. ${ }^{(19)}$

Segundo o autor mencionado acima, a não ocorrência dessas etapas (nascimento, crescimento e morte) no corpo humano, também pode ser considerado normal, tendo como critério o tipo de célula.
Sendo assim, o que acontece de maneira geral no caso do câncer, é que as células cancerosas, as quais são simplesmente células comuns, que sofreram alterações em algum fator genético (seja esta alteração por causas internas ou externas), seguem com a multiplicação das células (consideradas anômalas - transmitido às modificações genéticas para as demais células que agora nascem) sem que haja a morte celular. Isso causa desordem no corpo, favorecendo disfunções em sítios específicos. É imprescindível destacar que tais células anômalas, podem espalhar-se pelo resto do organismo. ${ }^{(15)}$

Quanto às causas dessas alterações celulares, essas podem ser internas ou externas ao organismo, podendo ainda, estarem ou não inter-relacionadas. É bom lembrar que alguns fatores, como a predisposição genética, a irradiação e até mesmo alimentação, contribuem para o desencadeamento destas, até mesmo, é possível a interação entre eles para aumentar a probabilidade da célula normal se transformar em maligna. No entanto, nenhum desses elementos, por si só, fornecem uma explicação plausível e suficiente para o surgimento da doença. ${ }^{(20)}$

Sobre a cura desta doença assim como em outras situações alguns tipos de câncer são considerados curáveis e outros 
não. Essa classificação se dá principalmente a partir da identificação do tipo de tumor e estágio de evolução em que esse câncer se encontra, assim, o diagnóstico precoce constitui ferramenta de extremo valor na luta contra o câncer, tendo em vista que a possibilidade de cura é ampliada quando o diagnóstico da doença é feito precocemente, em contrapartida, 0 diagnostico tardio, além de dificultar a possibilidade de cura, pode resultar em complicações até mesmo após o tratamento do câncer. ${ }^{(8)}$

É importante mencionar de modo geral, o tratamento instituído para o câncer, é considerado longo, resulta em sua maioria em marcas profundas aos clientes que por hora o fizeram, tendo em vista que, independentemente do tipo de câncer, o tratamento para esta doença, envolve muito estresse emocional. (20)

No entanto, se ocorrer o retardo para início do tratamento ou até mesmo a ausência do tratamento, as células cancerígenas, tendem a multiplicar-se e invadir outros órgãos e tecidos, agravando ainda mais o quadro de saúde do indivíduo, podendo deste modo, evoluir para a morte. Alguns estudos mostram que, os clientes que possuem classificação de câncer considerada não curável, podem durante anos, seguir com qualidade de vida como em outros casos de doenças crônicas, desde que seja instituído tratamento adequado para controle da doença. ${ }^{(8)}$

\subsubsection{Câncer de Colo Uterino}

O Câncer do Colo do Útero o qual também é denominado de câncer cervical, nada mais é que, o desenvolvimento desordenado de células com alteração em seu Ácido Desoxirribonucleico (DNA) do colo uterino, podendo levar ao comprometimento do tecido subjacente (estroma), e assim invadir estruturas e órgãos próximo ou à distância. (21)

Atualmente, essa neoplasia ainda se configura como um importante problema de saúde púbica a níveis globais, principalmente por apresentar-se como um dos maiores indicadores de morbimortalidade entre as mulheres, apresentando "aproximadamente $530 \mathrm{mil}$ casos novos por ano [...] sendo responsável pelo óbito de 265 mil mulheres por ano" no mundo, a expectativa para 2016, apenas no Brasil, é de 16.340 casos novos, com um risco estimado de 15,85 casos a cada 100 mil mulheres. (22) No Brasil, no ano de 2012, foi considerada a terceira doença mais incidente entre as mulheres ${ }^{(23)}$, sendo que, em 2013, passou a ser considerada a segunda maior causadora de mortalidade neste público. ${ }^{(15)}$

Na maioria das situações essa doença possui curso lento e silencioso, 
apresentando sintomatologia apenas em estágio avançado. Alguns dos sinais prodrômicos considerados são: dor pélvica, dor durante a relação sexual, sangramento vaginal, presença de secreção anormal em sua maioria fétida e alguns casos, queixas urinárias ou mesmo intestinais. ${ }^{(24)}$

De acordo com publicações do Instituto Nacional de Câncer (INCA) existem alguns fatores que podem deixar uma pessoa mais propensa ao câncer cervical, dentre estes, temos fatores que estão diretamente associados às condições socioeconômicas, a infecção por Papiloma Vírus Humana (HPV), a grande variação de parceiros sexuais, quantia de cigarros fumados, vida sexual promíscua do parceiro, precariedade ou falta de higiene íntima, uso prolongado de contraceptivos, a nuliparidade, a multiparidade e também o início precoce de atividades sexuais. ${ }^{(18)}$

Embora a situação atual do câncer de colo uterino represente um cenário preocupante, é importante frisar que esta é uma doença passível de prevenção (3). Sendo que uma das formas diagnósticas preventivas mais simples e eficazes para identificação desta é o exame Papanicolau, o qual é popularmente conhecido como exame de preventivo. (24)

O acompanhamento ginecológico regular constitui uma das medidas profiláticas mais eficazes contra a essa doença, sendo este, ainda integrado ao tratamento e acompanhamento deste cliente, mesmo que em caso cirúrgico, visto que, mesmo após termino de tratamento, o risco de recidiva da doença chega a atingir percentual de $35 \%$. (10)

Segundo publicações do INCA, existem duas categorias de carcinomas consideradas como principais: o carcinoma epidermoide e o adenocarcinoma. O primeiro acomete o epitélio escamoso e é tido como o mais incidente, o qual possui responsabilidade por cerca de $80 \%$ dos casos. O segundo acomete 0 epitélio glandular, é considerado raro, sendo responsável por apenas $10 \%$ dos casos. (21)

De acordo com Brunner e Suddarth (10), podem ainda ocorrer outros tipos de câncer no útero, tais como o melanoma, sarcoma e linfoma. As neoplasias do colo uterino são precedidas por uma série de alterações no epitélio escamoso do útero, as quais, se limitadas apenas ao epitélio escamoso do útero, recebem a denominação de Neoplasia Intra-epitelial Cervical (NIC).

A característica principal desta doença está na evolução que vai desde alterações de grau simples, até aos graus mais elevados de NIC e também de displasia, ao que se refere à NIC, esta por sua vez "tem origem em células metaplásicas imaturas que se alteram, 
provavelmente, devido a uma associação de fatores: agentes oncogênicos, perturbações imunitárias e características epidemiológicas", já a displasia, é basicamente o crescimento desorganizado do epitélio, ainda em fase inicial. ${ }^{(8)}$

As lesões cervicais precursoras apresentam-se em graus evolutivos, a considerar conceitos cito-histopatológico, podendo desta maneira, ser classificadas como NIC 1, classificação que indica lesões de baixo grau e NIC 2 e NIC 3, os quais indicam leões de alto grau. (26)

O Quadro 1 apresenta a discriminação utilizada para a diferenciação dos tipos de NICs:

Quadro 1 - Descrição da classificação dos tipos de NICs.

\begin{tabular}{|c|c|}
\hline & Tabela de Classificação das NICs \\
\hline GRAU NIC & DEFINIÇÃO \\
\hline NIC 01 & $\begin{array}{l}\text { Discreta alteração da arquitetura epitelial à custa de } \\
\text { proliferação de células imaturas, atipias celulares de discreta } \\
\text { a moderada, coilocitose de moderada a intensa, maturação } \\
\text { parcial com diferenciação e maturação citoplasmática até as } \\
\text { células superficiais, entretanto, núcleos volumosos e densos. }\end{array}$ \\
\hline NIC 02 & $\begin{array}{l}\text { Alterações mais acentuação da estratificação do epitélio, } \\
\text { maior de despolarização e proliferação de células imaturas } \\
\text { atípicas e menor grau de maturação citoplasmática. }\end{array}$ \\
\hline NIC 03 & $\begin{array}{l}\text { Elevada alteração da disposição das três camadas do epitélio. } \\
\text { Onde as células revelam redução da maturação, com dano ao } \\
\text { volume citoplasmático e elevação de volume nuclear. Os } \\
\text { núcleos são hipercromáticos, de cromatina grosseira e de } \\
\text { distribuição irregular. Pode haver observação de mitoses em } \\
\text { toda a espessura do epitélio, porém, a coilocitose, não é mais } \\
\text { observada normalmente. }\end{array}$ \\
\hline
\end{tabular}

Fonte: Adaptado de (SANTOS; CANNO, 2014. p. 43).

\subsection{Papanicolau ou citologia oncológica}

O exame popularmente conhecido entre as mulheres como preventivo recebe denominação de Papanicolau ou Citologia Oncológica do Colo Uterino, é tido como o principal método de prevenção ao câncer de colo cervical, por ser capaz de detectar lesões no útero e presença de fatores de risco, como o HPV. ${ }^{(4)}$
Toda mulher que tem ou já teve atividade sexual deve submeter-se a exame preventivo periódico, especialmente se estiver na faixa etária dos 25 aos 59 anos de idade, é preconizado que este seja feito pelo menos uma vez ao ano. O exame é realizado em qualquer Unidade Básica de Saúde (UBS), desde que se tenha um profissional habilitado para a realização deste. (24) 
É indispensável destacar, que, a realização deste procedimento preventivo pode reduzir a incidência desta doença ou no mínimo a gravidade dos efeitos nocivos. Deste modo, acredita-se que, havendo uma cobertura ampla do chamado, público-alvo, sendo esta de no mínimo $80 \%$, mais a garantia de diagnóstico e tratamento adequado, seria possível alcançar uma redução média de $60 \%$ a $90 \%$ da incidência do câncer cervical invasivo.

Vale colocar que, atualmente, já existem experiências em países considerados desenvolvidos, onde alcançou-se redução dessa doença em $80 \%$, justamente onde houve implantação com qualidade do rastreamento citológico, unindo cobertura, tratamento $\mathrm{e}$ acompanhamento das mulheres. (21)

O método é considerado simples, confiável e de baixo custo, consiste na inspeção da região genital e coleta de material citopatológico da endocervice e ectocervice, ou seja, da parte interior e exterior do colo uterino, para posterior análise laboratorial. (13)

O objetivo do exame de Papanicolau é basicamente detectar lesões precoces e proporcionar o diagnóstico inicial da doença, até mesmo antes da manifestação dos sintomas, de modo a aumentar o percentual de cura para esta. A eficácia da realização do exame citopatológico
Papanicolau tem sido reconhecida em nível mundial, como uma estratégia segura e eficiente para a detecção precoce do câncer do colo do útero e tem transformado o cenário de taxas de incidência e mortalidade por este câncer. ${ }^{(18)}$

A Figura 2 representa a realização do exame Papanicolau:

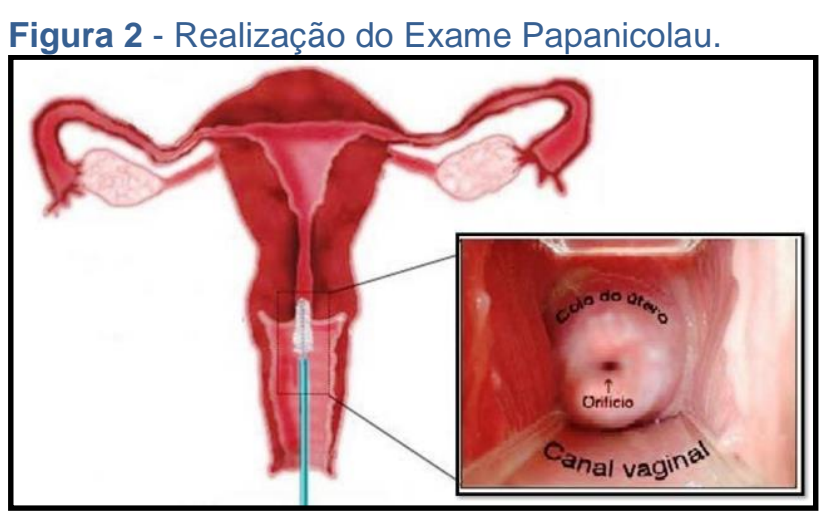

Fonte: Adaptado de BEMESTAR (2013).

Para a realização do exame, é necessário que a mulher receba orientações de preparo como, por exemplo, não realizar duchas vaginais, utilizar medicações vaginais ou, praticar relações sexuais, no período correspondente a, 48 horas, antes do exame, além de, não encontrar-se menstruada. Porém, sangramentos considerados atípicos, devem ser investigados. (23)

Os materiais utilizados para a coleta do exame citopatológico, são: Equipamentos de Proteção Individual (EPIs), especulo vaginal, escovinha endocervical e espátula de Ayres ${ }^{(4)}$. 
A Figura 3 apresenta tais materiais para a realização do exame Papanicolau em pacientes:

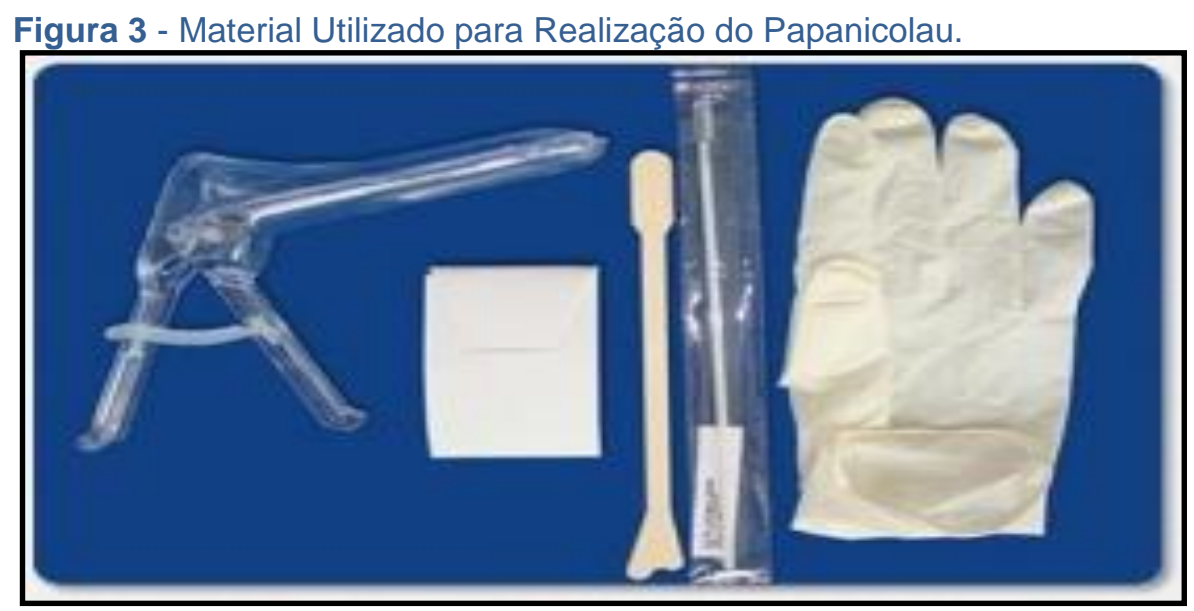

Fonte: IMEDIQ (2014)

De acordo com Brasil ${ }^{23)}$, o exame é feito com a mulher em posição ginecológica, em seguida o profissional realiza a introdução do espéculo no canal vaginal (para facilitar a visualização do colo uterino), ainda com 0 especulo posicionado, realiza-se a coleta do material da ectocérvice (parte exterior do colo), através da utilização da espátula de Ayres, a amostra coletada deve ser disposta na lâmina, sendo que a disposição desse material deve comprometer apenas metade do espaço da lâmina, sendo depositado na mesma de modo transverso.

Posteriormente, faz-se a introdução da escovinha cervical no canal uterino, para coleta do material da endocérvice (parte interior do colo), o material deve ser disposto na parte que ainda se encontra limpa da lâmina, de modo longitudinal, através de movimento giratório.

O mesmo autor informa que, após a disposição do material coletado na lâmina (tanto da ectocérvive e como da endocérvice), faz-se uso do fixado citológico na lâmina, para então, enviá-la adequadamente identificada para laboratório de análise citológica.

É importante lembrar que, no momento de disposição do material citológico na lâmina, não pode haver sobreposição da amostra, para que não haja comprometimento da visualização celular. Após o término do procedimento, os materiais utilizados na coleta, são descartados.

Faz-se indispensável salientar a importância da realização deste exame para o diagnóstico precoces da neoplasia, 
visto que, segundo o MS se a doença for identificada ainda em fase inicial 0 prognóstico de cura pode chegar até 100\% de chances. ${ }^{(5)}$

Sabendo das evidencias que ligam a ocorrência do câncer cervical, a presença do vírus HPV, as técnicas para detecção deste, foram aprimorando-se. Atualmente, existem estudos que visam à utilização de testes moleculares, para rastreamento do DNA do HPV. Considerando que o mesmo ainda possui especificidade baixa, se comparado ao Papanicolau, sua recomendação pode estar apenas para mulheres de idade igual ou superior a 35 anos. (27)

Seguindo orientações do autor citado acima, outro exame utilizado para diagnóstico precoce do câncer cervical é a chamada colposcopia, a qual parte da análise cuidadosa do colo uterino e da vagina, por meio de lentes aumentadas, a fim de favorecer a visualização de lesões que antecedem o câncer e assim, possibilitar o tratamento das lesões antes do agravamento do quadro. São submetidas ou encaminhadas para realização deste procedimento, mulheres que apresentaram testes moléculas positivo para o HPV ou, as que o exame Papanicolau revelou alguma alteração.Salvo lembrar que, caso durante o processo de colposcopia seja encontrado alguma alteração, recomenda-se, a realização de outro procedimento, a chamada biópsia, a qual também é considerada uma ferramenta eficaz para diagnóstico de câncer, consiste na retirada de um ou mais fragmentos de área alterada do colo do útero, durante o exame clínico ou na colposcopia, para exame histopatológico. ${ }^{(27)}$

O Quadro 2 apresenta uma lista com os possíveis diagnósticos citopatológicos anormais, os quais estão seguidos de respectivas recomendações de condutas:

Quadro 2 - Recomendações iniciais após resultado de exame citopatológico anormal.

\begin{tabular}{|c|c|c|c|c|}
\hline & Result & dos & $\begin{array}{l}\text { Grau de } \\
\text { suspeição }\end{array}$ & Conduta \\
\hline \multirow{4}{*}{$\begin{array}{l}\text { Atipias de } \\
\text { significado } \\
\text { indeterminado }\end{array}$} & \multirow{2}{*}{$\begin{array}{l}\text { Em células } \\
\text { escamosas }\end{array}$} & $\begin{array}{l}\text { Provavelmente não } \\
\text { neoplásica. }\end{array}$ & Menor & $\begin{array}{l}\text { Repetir a citologia em } 06 \text { meses } \\
\text { ( }>30 \text { anos) ou }(<30 \text { anos). }\end{array}$ \\
\hline & & $\begin{array}{l}\text { Não se pode afastar } \\
\text { lesão de alto grau. }\end{array}$ & Maior & $\begin{array}{l}\text { Encaminhamento } \\
\text { colposcopia. }\end{array}$ \\
\hline & \multirow{2}{*}{$\begin{array}{l}\text { Em células } \\
\text { glandulares }\end{array}$} & $\begin{array}{l}\text { Provavelmente não } \\
\text { neoplásica }\end{array}$ & Maior & $\begin{array}{l}\text { Encaminhamento } \\
\text { colposcopia. }\end{array}$ \\
\hline & & $\begin{array}{l}\text { Não se pode afastar } \\
\text { lesão de alto grau. }\end{array}$ & Maior & $\begin{array}{l}\text { Encaminhamento } \\
\text { colposcopia. }\end{array}$ \\
\hline
\end{tabular}




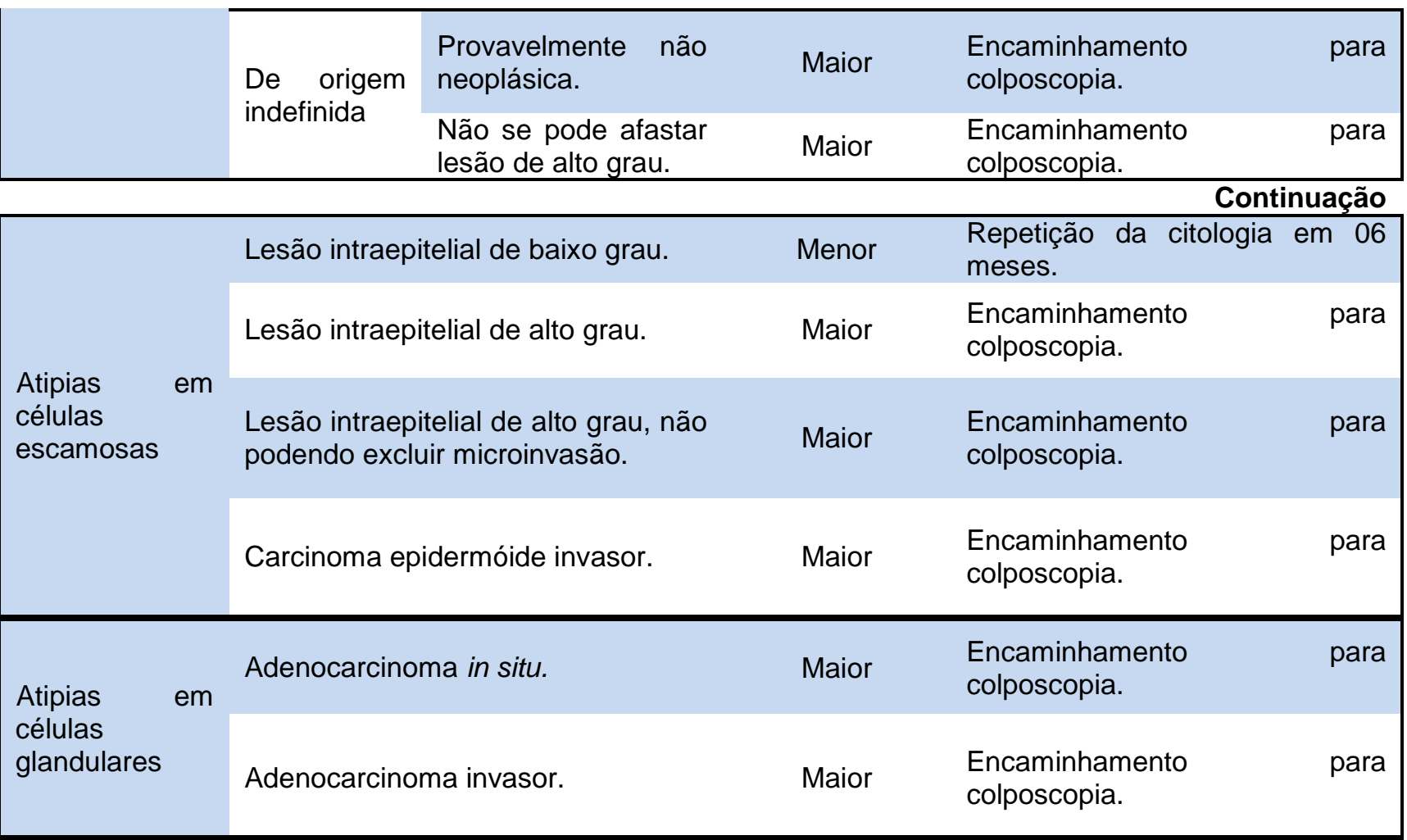

Fonte: BRASIL, 2013.

É de real importância que, além de realizar o procedimento de coleta de exame citopatológico, a mulher tenha a preocupação de retornar a unidade de saúde para buscar o resultado da análise laboratorial da amostra, para que se necessário, seja iniciado tratamento o mais precoce possível.

Salienta-se que, além desses resultados, a mulher pode apresentar algum tipo de infecção ou inflamação, que necessitará ser tratado, sendo em muitas situações necessário tratar também o parceiro sexual.

Deste modo, o resultado faz-se de suma importância para a saúde da mulher, sendo que este, só deve ser entregue por um profissional capacitado, e que, entenda a importância do processo. (23)

\subsection{Evolução das políticas de atenção a saúde da mulher}

No Brasil, as Políticas de Atenção à Saúde da Mulher, sempre surgiram de complexas e amplas discussões, isso se deu principalmente devido à forma com que a mulher era socialmente vista na época: um ser sexual, com responsabilidades domésticas, reprodutivas e de cuidados com filhos e demais componentes familiares. (28)

Deste modo, a saúde da mulher passou a ser incorporada ao âmbito das políticas de saúde, a partir do século XX, e abarcava apenas temas relacionados à 
gravidez e ao parto, no sentido de proporcionar um corpo saudável e propício para criação de um novo corpo saudável, compatível com a vida e expectativas sociais, deixando a saúde da mulher descoberta na maioria dos seus seguimentos, sendo ainda, que esta política, atendia apenas os considerados grupos de risco. (29)

Diante do visível contexto de desigualdade, as mulheres passaram a organizar-se e defender seus conceitos e ideais. Passaram a lutar por uma atenção a saúde de modo integral, que fosse além do período gravídico e do parto, e que incluísse todos os grupos femininos. Contextualizaram e colocou em seus discursos, a mulher como ser também adoecedor e com necessidades de cuidados com a saúde bem como o homem. (30)

Com base nesses argumentos, começaram a surgir propostas de reorganização deste eixo, assim, em 1984, o MS divulgou a proposta do "Programa de Assistência Integral à Saúde da Mulher (PAISM), marcando, sobretudo, uma ruptura conceitual com os princípios norteadores da política de saúde das mulheres". (29)

De acordo com Brasil (31), o PAISM possui como objetivo primordial a assistência de modo integral (em todos os níveis de complexidade) a saúde da mulher, visando, principalmente a redução de morbimortalidade deste grupo. Brasil (29) coloca que o mesmo "[...] incluía ações educativas, preventivas, de diagnóstico, tratamento e recuperação, englobando a assistência à mulher em clínica ginecológica, no pré-natal, parto e puerpério, no climatério, em planejamento familiar, DST, câncer de colo de útero e de mama, além de outras necessidades identificadas a partir do perfil populacional das mulheres".

É indispensável destacar a contribuição do PAISM, principalmente, ao considerar 0 redimensionamento do conceito tido sobre o corpo feminino, ao abordar em especial, a integralidade deste ser. Assim, a adoção do PAISM, representou um importante passo em direção ao conhecimento de direitos das mulheres, valendo citar aqui, o direito sexual e reprodutivo. (28)

A Estratégia e Saúde da Família (ESF) constitui uma proposta de reorganização da atenção primária, deste modo, pode-se colocar que é basicamente, a reestruturação de estratégias de ação para os conhecidos Postos de Saúde, no qual, a equipe de saúde recebe uma responsabilidade mais ampla no que se refere à promoção e prevenção de saúde em um contexto coletivo e individual, dentro 
de uma área delimitada, denominada neste contexto, área de abrangência. ${ }^{(6)}$

Em publicação do MS, encontra-se que a ESF, caracteriza-se como modelo primordial de atenção primária, ou seja, designa o eixo central da atenção a saúde da população. Deste modo, é considerada a porta de entrada para atendimento no sistema de saúde. (32)

Este modelo inclui várias etapas de trabalho e para que funcione como o esperado, é necessário que possua uma equipe multidisciplinar dotada de saberes que se completem mediante ao atendimento da população, assim: "[...] inicia-se com $o$ ato de acolher, escutar e oferecer resposta resolutiva para a maioria dos problemas de saúde da população, minorando danos e sofrimentos e responsabilizando-se pela efetividade do cuidado, ainda que este seja ofertado em outros pontos de atenção da rede, garantindo sua integralidade". (33)

É indispensável que a equipe da ESF possua perfil resolutivo, sendo capaz de assistir os problemas comuns a população sob sua responsabilidade sanitária, de modo que atue como um filtro, onde se consiga resolver significativa parte dos problemas sem necessidade de encaminhar para outros níveis de assistência. Assim sendo, essa estratégia deve fazer uso de meios que possibilitem promover mudança de hábitos e valores da população, de modo que reflitam em qualidade de vida para o grupo sob sua respectiva responsabilidade. ${ }^{(34)}$

Portanto, o trabalho em equipe constitui o pilar para a qualidade deste serviço, fazendo-se mandatário que os conhecimentos e habilidades dos envolvidos, integrem-se de modo a somar para o fornecimento do serviço ao usuário do sistema. Devem fazer parte dessa equipe: médico, enfermeiro, Agentes Comunitárias de Saúde (ACS), técnico de enfermagem, cirurgião dentista e técnico em saúde bucal. (33)

Quando falamos na atuação do ACS, é indispensável fazer alusão ao processo de busca ativa, principalmente quando se pensa em um resultado de exame Papanicolau, que apresentaram alterações significativas e exigem intervenção da equipe de saúde. A busca ativa constitui basicamente uma ação de localização de pessoas em situação de vulnerabilidade $e$, é considerada uma forte aliada da assistência em saúde. (33)

O conteúdo exposto faz perceber a importância da proposta da ESF, e leva a percepção da necessidade da qualidade no fornecimento desse serviço, principalmente para a prevenção de doenças, não apenas no contexto individual, como também no contexto coletivo, visto que este modelo 
não se centra apenas no tratamento da doença propriamente dito, mas em promoção de mudanças de hábitos e estilos de vida que contribuam para existência desta, onde a família é o foco e não mais a doença. ${ }^{(6)}$

Vale mencionar que, a partir do surgimento do PAISM, muitas foram às evoluções no que se referem a programas de atenção a saúde da mulher. (28) Dentro do contexto câncer, por exemplo, a partir das políticas do PAISM que passaram a surgir modelos de programas de detecção precoce do câncer de colo de útero, com publicações ademais manuais técnicos orientando tanto os estados como também os municípios. ${ }^{(35)}$

No Brasil, as atividades para controle do câncer, foram materializadas em 1990, sob a coordenação do Instituto Nacional de Câncer (INCA), sendo que, especificamente em relação ao colo do útero, foi criado pelo MS o Programa Nacional de Controle do Câncer CérvicoUterino (PNCCU). Mais tarde, em 1996, em 04 municípios e em 01 estado, foi realizado pelo INCA/MS um projeto piloto, denominado "Programa Viva Mulher", o qual objetivava o controle do câncer de colo de útero. (27)

Em 1997, o MS por meio do PNCCU, conseguiu implantar dentro dos programas de atenção básica a saúde, procedimentos simples e de baixo custo, que auxiliaram de maneira significativa na prevenção $e$ detecção precoce do câncer de colo de útero. ${ }^{(35)}$

É importante destacar, que, de acordo com Brasil (31), os objetivos do PNCCU, consistiam em:

- Definição da população-alvo, método e intervalo de rastreamento; e meta de cobertura;

- Infraestrutura assistencial nos três níveis de atenção;

- Sistema de informação para monitorar todo o processo de rastreamento;

- Diretrizes de diagnóstico e tratamento estabelecidas;

- Processo de capacitação e treinamento continuados de profissionais de saúde;

- Informação para a população-alvo;

- Garantia da qualidade das ações;

- Compromisso técnico e político dos gestores para continuidades das ações;

- Garantia de suporte financeiro.

A mesma literatura afirma que, em virtude da relevância demonstrada por meio dos valores epidemiológicos de incidência da doença no Brasil, foi criado em 2010, por meio da portaria № 310 , de 10 de fevereiro de 2010, o chamado Grupo de Trabalho, o qual foi criado no intuito de avaliar o PNCCU, elaborar objetivos e propostas de aperfeiçoamento. ${ }^{(31)}$ 
Considerando o exposto, fica clara a necessidade de elaboração de melhores estratégias envolvendo a temática, principalmente ao destacar, que embora o câncer de colo de útero seja uma doença que pode ser prevenida e detectada precocemente, ainda é uma das maiores causas de morbimortalidade entre as mulheres. ${ }^{(35)}$

No que se refere a aprimoramento e desenvolvimento de novas estratégias, vale citar a vacina contra o Papiloma Vírus Humana (HPV), vírus este, associado a diversas formas de câncer, em especial no gênero feminino. Esse vírus possui grande capacidade de contagio, sendo a principal forma de transmissão por contato direto entre mucosa ou mesmo pele contaminada. (25)

O autor citado acima, atualmente existe uma estimativa, que prevê que cerca de $50 \%$ da população esteja contaminada com este vírus, é importante colocar, que a maioria dessas infecções são transitórias e combatidas pelo sistema imunológico, sendo que das pessoas contaminadas, apenas $10 \%$ desenvolveram algum tipo de lesão cancerígena.

Visando combater a disseminação do vírus, foram criadas as vacinas profiláticas e terapêuticas contra o HPV, a primeira tem-se mostrado muito efetiva, visto que combate a várias formas do vírus, é denominada quadrivante, pois em sua formulação possuem características contra 04 tipos de vírus, no entanto, esta metodologia não elimina a proposta do exame de preventivo, visto que, a vacina não combate a todas as formas do vírus e nem mesmo a outras doenças sexualmente transmissíveis, alheias ao vírus. A segunda, considerada vacina terapêutica, ainda possui eficácia de baixa qualidade, no entanto já está comprovado cientificamente, que esta também é uma medida de profilaxia, visto que também estimula a prevenção contra alguns tipos de vírus. (37)

\subsection{A importância do enfermeiro na prevenção do câncer cervical}

Fazendo referência a ESF o profissional enfermeiro surge neste contexto como integrante desta equipe e gestor do serviço de saúde. De acordo com a lei do exército profissional $n^{\circ} 7.498$, de 25 de junho de 1.986, a direção, chefia, organização, planejamento, coordenação e avaliação dos serviços prestados em instituições de saúde, correspondem a funções privativas do profissional enfermeiro. ${ }^{(38)}$

Figueiredo (33) coloca ainda como atividades de responsabilidade deste profissional, realizar consultas de enfermagem de modo a atender todos os famílias e indivíduos cadastradas sob o 
território de sua responsabilidade, gerir (prover e prever) insumos necessários para funcionalidade da instituição e realizar procedimentos.

Ligado ao exercício da atividade, outra função deste profissional, é realizar orientações do procedimento do exame Papanicolau, assim como da importância da realização deste, solicitar exames, prescrever medicamentos de acordo com o protocolo da instituição, encaminhar adequado a demais componentes da equipe multiprofissional diante da detecção de alterações citológicas, realizar visitas domiciliares, detectar situações de vulnerabilidade bem como, planejar e executar atividades voltadas para 0 diagnóstico precoce, ademais, desenvolver atividades de educação em saúde em grupo, com vistas, principalmente a divulgação principais fatores de risco e apresentação de condutas consideráveis saudáveis. ${ }^{33}$; 39)

Ao que se refere às atividades de educação em saúde, o enfermeiro é inserido nesse contexto, a considerar a relação diálogo-reflexiva, entre o cliente e este profissional. Pois, tal profissional, além de possuir arcabouço de conhecimentos teórico e científico, desenvolve atividades mais próximas ao cliente e comunidade, 0 que permite uma relação mais estreita entre esses elementos, favorecendo que, por meio do diálogo, a dimensão de saúdedoença seja percebida pelo cliente, estimulando sua reflexão e mudança de hábitos. ${ }^{(40)}$

Ainda abordando a questão de educação em saúde, ao perceber os resultados que esta pode alcançar, no controle e combate dos mais diversos agravos, o MS passou a investir em diversas estratégias. ${ }^{(41)}$

Considerando a temática do câncer, por exemplo, podemos citar entre as mesmas, a campanha denominada Outubro Rosa, a qual nasceu em 1990, com vistas a estimular a participação popular na prevenção e combate ao câncer de mama. Atualmente, a campanha ganhou força e apoio de outros órgãos, ampliando seus aspectos, deste modo, trabalha com ferramentas que vão desde a conscientização sobre 0 câncer até métodos de rastreamento deste, facilitando por meio de ações intensificadas o acesso da população a este serviço. ${ }^{(42)}$

O trabalho de prevenção estende-se desde um atendimento individualizado até medidas coletivas, é importante colocar que todas as ações desenvolvidas, devem considerar crenças, valores, culturas, religião e arcabouço de conhecimento da população, a fim de ampliar os resultados positivos do trabalho desempenhado $\mathrm{e}$ aceitação do público. (39) 
Nesse sentido, percebe-se como indispensável para este serviço, a presença do profissional enfermeiro. Vale destacar ainda, no que se refere ao câncer de colo uterino, o enfermeiro possui figura ainda mais relevante, ressaltando que é responsabilidade deste profissional a promoção de saúde e a prevenção de doenças e agravos, bem como ações que possibilitem tratamento e reabilitação, vale deste modo citar a resolução Conselho Federal de Enfermagem (COFEN) № $381 / 2011$, a qual coloca no Art. $1^{\circ}$ que, "no âmbito da equipe de Enfermagem, a coleta de material para colpocitologia oncótica pelo método de Papanicolau é privativa do Enfermeiro". (43)

Deste modo, é importante que o enfermeiro assuma o seu papel enquanto profissional com tal arcabouço de responsabilidades $e$ busque meios $e$ estratégias que alcancem as mulheres, principalmente as que possuem fatores de risco para o desenvolvimento desta doença, para encorajá-las e auxiliá-las a formular suas próprias metas de saúde, acolhendo, acompanhando, orientando, esclarecendo duvidas e fornecendo novos conhecimentos sobre a doença, esquematizando atividades comunitárias e individuais para que haja eficácia na promoção de saúde, e quando necessário auxiliar no enfrentamento da doença. ${ }^{(44)}$
O enfermeiro possui papel de extremo valor frente à prevenção, não somente ao que se refere ao câncer cervical, como também prevenção de outras doenças e agravos, sendo de fundamental valor a conduta adotada por este profissional ao longo de um atendimento, a destacar que esta, pode ser um fator determinante na assistência prestada ao cliente. ${ }^{(45)}$

\section{CONSIDERAÇÕES FINAIS}

Ao término dessa pesquisa, permitiu conhecer um pouco sobre o alarmante e preocupante cenário que envolve o câncer cervical, doença essa que, embora seja passível de prevenção, constitui atualmente um grave problema de saúde pública, não apenas no Brasil mais a nível mundial, o que valoriza nesse contexto, a produção de estudos e discussões em torno da temática, de maneira a contribuir para mudança de tal situação.

É importante que tanto a população quando os profissionais de saúde tenham em mente, que o diagnóstico precoce da doença pode aumentar a perspectiva de cura. Esse entendimento pode resultar em ampliação da aderência ao tratamento e possivelmente, redução de maiores danos à saúde do cliente. Além, do fato, de que os gastos com prevenção são significativamente inferiores a gastos com o tratamento da doença. 
A equipe de enfermagem, por sua vez, em virtude de possuir relação mais próxima à comunidade e formação mais generalista, com focos em humanização e educação em saúde, pode contribuir de maneira significativa para o enfrentamento do câncer de colo uterino. Sendo desta maneira, de extremo valor, que o enfermeiro reconheça $o$ seu papel e assuma suas responsabilidades diante desse contexto, buscando estratégias que alcancem as mulheres de maneira geral e fortaleça a temática de prevenção.

Todavia, é necessária também a ação do poder público, principalmente a considerar populações com baixa condição socioeconômica e pouca escolaridade, as quais necessitam dessas ações para terem acesso ao sistema de saúde. Somente assim, poder-se-á cumprir um dos princípios básicos da Constituição Brasileira, o qual coloca a saúde como um direito de todos e dever do Estado.

\section{REFERÊNCIAS}

1. Carvalho, SCB, Santos, MD; Barros, ÂMS. A Incidência de Lesões PréCancerígenas e Câncer de Colo Uterino em Mulheres do Município de Mirandiba-PE. Rev. Saú. Colet. Deb. Brasil, 2011. [citado em 03 de outubro de 2015]. Disponível em: <http://www.fis.edu.br/revistaenfermagem/ artigos/vol01/carvalhosantosbarros2011.pd $\mathrm{f}>$.

2. Costa, JHG et al. Prevenção do Câncer de Colo do Útero em Comunidades Ribeirinhas Atendidas pelo Programa Luz na Amazônia, Estado do Pará, Brasil. Rev. Pan-Amaz Saú. Brasil, 2011. [citado em 03 de outubro de 2015]. Disponível em: <http://scielo.iec.pa.gov.br/scielo.php?pid= S217662232011000400003\&script=sci_art text>.

3. Arruda, FS et al. Conhecimento e Prática na Realização do Exame de Papanicolaou e Infecção Por HPV Em Adolescentes de Escola Pública. Rev. Parae. de Med. Brasil, 2013. [citado em 03 de outubro de 2015]. Disponível em: <http://files.bvs.br/upload/S/01015907/2013/v27n4/a4078.pdf>.
4. Siqueira, GS. et al. Citopatologia Como Prevenção do Câncer do Colo Uterino. Cadernos de Graduação - Ciências Biológicas e da Saúde Unit. Aracaju, 2014. [citado em 03 de outubro de 2015]. Disponível em: < https://periodicos.set.edu.br/index.php/cad ernobiologicas/article/view/1179>.

5. Villani, MS. O Exame Preventivo do Câncer Cérvico-Uterino na Visão de Mulheres Atendidas em Uma ESF. 2012. 22 f. Monografia (Especialização). Universidade Regional do Noroeste do Estado do Rio Grande do Sul (UNIJUí). Departamento de Ciências da Vida DC Vida. Curso de Pós-Graduação em Oncologia. [citado em 04 de novembro de 2016]. Disponível em:< http://bibliodigital.unijui.edu.br:8080/xmlui/b itstream/handle/123456789/799/Melania\% 20Villani.pdf?sequence $=1>$.

6. Rosa, WAG; Labate, RC. Programa Saúde da Família: A Construção de um Novo Modelo de Assistência. Rev. Latinoam Enfer. São Paulo, 2005. [citado em 26 de novembro de 2015]. Disponível em: $<$ http://www.scielo.br/pdf/rlae/v13n6/v13n6 a16.pdf>. 
7. Rocha, JM; Santos, VLO; Cunha, KJB. Câncer do Colo do Útero: Desafios para o Diagnóstico Precoce. Rev. Saú. Foc. Teres., 2014. [citado em 03 de outubro de 2015]. Disponível em: <http://www4.fsanet.com.br/revista/index.p $\mathrm{hp} /$ saudeemfoco/issue/view/32>.

8. Santos, JA; Canno, VAC. Conhecimento de Mulheres Universitárias em Relação à Importância do Exame Citopatológico de Papanicolaou. São Paulo, 2014. Monografia. $99 \mathrm{f}$. UNISALESIANO - Centro Universitário Católico Salesiano. [10 de maio de 2016]. Disponível em: <http://www.unisalesiano.edu.br/biblioteca/ monografias/57525.pdf>.

9. Kawamoto, EE. Anatomia e Fisiologia Humana. São Paulo: EPU - 1988.

10. Brunner; Suddarth. Tratado de enfermagem médico-cirúrgica. 12. Ed. Rio de Janeiro: Guanabara Koogan, 2011.

11. Dângelo; JG, Fattini; CA. Anatomia Humana Básica. São Paulo: Atheneu, 2005.

12. Ricci, SS. Enfermagem Materno Infantil - Neonatal e Saúde da Mulher. Rio de Janeiro: Guanabara Koogan, 2008.

13. BRASIL. Ministério da Saúde. Prevenção do Câncer do Colo do Útero Manual Técnico: Organizando a Assistência. Brasília, 2002a. [citado em 25 de novembro de 2015]. Disponível em: <http://bvsms.saude.gov.br/bvs/publicacoe s/inca/manua_assistencia.pdf>.

14. SOBOTTA. Atlas de Anatomia Humana: Órgãos Internos, v. 02 / Rio de Janeiro: Guanabara Koogan, 2012.

15. BRASIL. Ministério da Saúde. Instituto Nacional de Câncer José Alencar Gomes da Silva (INCA). ABC do Câncer: Abordagens Básicas para Controle do Câncer. Rio de Janeiro, 2012. [citado em 26 de novembro de 2015]. Disponível em: $<$ http://bvsms.saude.gov.br/bvs/publicacoe s/inca/abc_do_cancer_2ed.pdf>.
16. Almeida, VL. et al. Câncer e Agentes Antineoplásicos Ciclo-Celular Específicos e Ciclo-Celular não Específicos que Interagem com o DNA: Uma Introdução. Rev. Quím. Nov. Brasil, 2005. [citado em 24 de novembro de 2015]. Disponível em: <http://www.scielo.br/pdf/qn/v28n1/23048. pdf $>$.

17. Guerra, MR; Gallo, CVM; Mendonça, GA; Silva, M. Risco de Câncer no Brasil: Tendências e Estudos Epidemiológicos mais Recentes. Rev. Bras.Cancer. Brasil, 2005. [citado em 24 de novembro de 2015]. Disponível em: <http://www.inca.gov.br/rbc/n_51/v03/pdf/r evisao1.pdf>. Acesso em: 24 novembro 2015.

18. BRASIL. Ministério da Saúde. Instituto Nacional de Câncer José Alencar Gomes da Silva (INCA). Estimativa / 2014 Incidência de Câncer no Brasil. Rio de Janeiro, 2014b. [citado em 04 de junho de 2016]. Disponível em: <http://www.saude.sp.gov.br/resources/ses /perfil/gestor/homepage/outrosdestaques/estimativa-de-incidencia-decancer-

2014/estimativa_cancer_24042014.pdf>.

19. BRASIL. Instituto Nacional de CâncerINCA. Políticas Públicas de Saúde. Fisiologia do Câncer. Capítulo 02. Brasil, 2003. [citado em 09 de outubro de 2016]. Disponível em: $<$ http://www.inca.gov.br/enfermagem/docs/ cap2.pdf>.

20. SILVA, S. S.; AQUINO, T. A. A.; SANTOS, R. M. O Paciente com Câncer: Cognições e Emoções a Partir do Diagnóstico. Rev. Bras. Tera. Cognit. BRASIL, 2008. [citado em 04 de junho de 2016]. Disponível em: < http://pepsic.bvsalud.org/pdf/rbtc/v4n2/v4n 2a06.pdf>.

21. BRASIL. Instituto Nacional de CâncerINCA. Programa Nacional de Controle do Câncer de Colo de Útero. Brasil, 2011c. [citado em 24 de novembro de 2015]. 
Disponível

em: <http://www1 inca.gov.br/inca/Arquivos/PR OGRAMA_UTERO_internet.PDF>.

22. BRASIL. Instituto Nacional de Câncer José Alencar Gomes da Silva (INCA). Acesso a Informação. Controle do Câncer de Colo de Útero. Brasil, 2016a. [citado em 04 de junho de 2016]. Disponível em:<http://www2.inca.gov.br/wps/wcm/con nect/acoes_programas/site/home/nobrasil/ programa_nacional_controle_cancer_colo_ utero/conceito_magnitude>.

23. BRASIL. Ministério da Saúde. Secretaria de Assistência à Saúde. Instituto Nacional de Câncer. Falando Sobre Câncer do Colo de Útero. Rio de Janeiro, 2002b. [citado em 25 de novembro de 2015]. Disponível em: <http://bvsms.saude.gov.br/bvs/publicacoe s/falando_cancer_colo_utero_p1.pdf > .

24. Casarin, MR; Piccoli, JCE. Educação em Saúde para Prevenção do Câncer de Colo do Útero em Mulheres do Município de Santo Ângelo/RS. Rev. Ciên. Saú. Colet. Brasil, 2009. [citado em 24 de novembro de 2015]. Disponível em: <http://www.scielosp.org/pdf/csc/v16n9/a2 9v16n9.pdf $>$.

25. BRASIL. Secretaria de Estado da Saúde. Coordenadoria de Controle de Doenças. Centro de Vigilância Epidemiológica. Divisão de Imunização. Informe Técnico - Vacina Contra o Papiloma Vírus Humano (HPV). São Paulo, 2014a. [citado em 05 de junho de 2016]. Disponível em: <http://www.cve.saude.sp.gov.br/htm/imuni /pdf/HPV14_INFORME_TECNICO.pdf>.

26. Santos, ALF. et al . Human papillomavirus viral load in predicting highgrade CIN in women with cervical smears showing only atypical squamous cells or low-grade squamous intraepithelial lesion. Sao Paulo Med. J., São Paulo, 2003. [citado em 09 de outubro de 2015]. Disponível http://www.scielo.br/pdf/spmj/v121n6/2041 8.pdf $>$.

27. BRASIL. Ministério da Saúde. Instituto Nacional de Câncer José Alencar Gomes da Silva (INCA). Diretrizes Brasileiras para o rastreamento Do CânCer Do Colo Do Útero. Rio de Janeiro, 2011a. [citado em 09 de outubro de 2015]. Disponível em: $<$ http://www1.inca.gov.br/inca/Arquivos/Dir etrizes.PDF>.

28. OSIS, MJMD. Centro de Pesquisa das Doenças Materno-Infantis de Campinas. Paism: um marco na abordagem da saúde reprodutiva no Brasil. Rio de Janeiro, 1998. Disponível

em: $<$ https://www.nescon.medicina.ufmg.br/bibl ioteca/imagem/0734.pdf>.

29. BRASIL. Ministério da Saúde. Secretaria de Atenção à Saúde. Departamento de Ações Programáticas Estratégicas. Política Nacional de Atenção Integral à Saúde da Mulher - Princípios e Diretrizes. Série C. Projetos, Programas e Relatórios. Brasília, 2004. [citado em 11 de maio de 2016]. Disponível em:<http://bvsms.saude.gov.br/bvs/publica coes/politica_nac_atencao_mulher.pdf>.

30. BRASIL. Depto. de Ciências Sociais da Ensp/ Fiocruz. Caderno de Saúde Pública. Saúde da Mulher. Rio de Janeiro, 1991. [citado em 11 de maio de 2016]. Disponível em:

$<$ http://www.scielosp.org/pdf/csp/v7n2/v7n 2a01.pdf>.

31. BRASIL. Prefeitura Municipal de Florianópolis. Secretaria Municipal de Saúde. Diretoria de Atenção Primária. Gerência de Programas Estratégicos. Programa Saúde da Mulher. Protocolo de Atenção Integral à Saúde da Mulher. Florianópolis, 2010. [citado em 11 de maio de 2016]. Disponível em: <http://www.pmf.sc.gov.br/arquivos/arquivo s/pdf/05_08_2011_9.34.09.68795919f7565 362b22dc5dadfadfe38.pdf>.

32. BRASIL. Eixo Central Ordenador do Sistema de Saúde de Florianópolis. 
Secretaria Municipal de Saúde. Atenção Primária - Estratégia de Saúde da Família. Florianópolis, 2009. [citado em 26 de novembro de 2015]. Disponível em: <http://www.pmf.sc.gov.br/arquivos/arquivo s/pdf/05_11_2009_8.59.50.a3dd63a65dd7 0d7781131c03ce4e8a9d.pdf>.

33. Figueiredo, ENA. Estratégia Saúde da Família na Atenção Básica do SUS. Módulo Político Gestor, 2010. [citado em 26 de novembro de 2015]. Disponível em: $<$ http://www.unasus.unifesp.br/biblioteca_v irtual/esf/2/unidades_conteudos/unidade 05 /unidade05.pdf>.

34. BRASIL. Ministério da Saúde. Secretaria de Políticas de Saúde e Departamento de Atenção Básica. Cadernos de Atenção Básica - Programa Saúde da Família. Brasília, 2000a. [citado em 26 de novembro de 2015]. Disponível em:

<http://bvsms.saude.gov.br/bvs/publicacoe s/caderno_atencao_basica_n1_p1.pdf>.

35. Soares, MBO; Silva, SR. Análise de um Programa Municipal de Prevenção do Câncer Cérvico Cérvico-Uterino. Rev. Brasil. Enfer. - REBEn. Brasil, 2010. [citado em 11 de maio de 2016]. Disponível em: $<$ http://www.scielo.br/pdf/reben/v63n2/02.p $\mathrm{df}>$.

36. BRASIL. Ministério da Saúde. Instituto Nacional de Câncer (INCA). Sumário Executivo - Plano de Ação para Redução da Incidência e Mortalidade por Câncer do Colo do Útero. Rio de Janeiro, 2010. [citado em 26 de novembro de 2015]. Disponível em:

<http://www1.inca.gov.br/inca/Arquivos/su mario_colo_utero_versao_2011.pdf>.

37. Zardo, GP. et al. Vacina como Agente de Imunização contra o HPV. Rev. Revis. Review. Brasil, 2013. [citado em 05 de junho de 2016]. Disponível em: <http://www.scielosp.org/pdf/csc/v19n9/14 13-8123-csc-19-09-3799.pdf>.

38. BRASIL. Presidência da República Casa Civil Subchefia para Assuntos
Jurídicos. Lei $n^{\circ} 7.498$, de 25 de jun. de 1986. Dispõe sobre a regulamentação do exercício da enfermagem, e dá outras providências. Brasil, 1986. [citado em 03 de outubro de 2016]. Disponível em: http:<//www.unama.br/novoportal/bibliotec a/attachments/article/126/Manual\%20ABN T\%20UNAMA\%2004-08-2014.pdf>.

39. Paula, CG et al., Atuação do Enfermeiro da Atenção Básica Frente ao Controle do Câncer Uterino: Revisão de Literatura. Rev. Cen. Univers. New. Pai. Brasil, 2012. [citado em 09 de outubro de 2016]. Disponível em: <http://blog.newtonpaiva.br/pos/wpcontent/uploads/2013/04/PDF-E5S33.pdf $>$.

40. Pinheiro, A. K. B. Enfermagem e Práticas de Educação em Saúde. Rev. Rene. Fortaleza, 2011. [citado em 04 de novembro de 2016]. Disponível em:< http://www.revistarene.ufc.br/vol12n2_pdf/ a01v12n2.pdf>.

41. Jesus, AF; Ribeiro, ER. Educação na Área da Saúde: Importância da Atuação do Enfermeiro. Caderno Saúde e Desenvolvimento. Rev. Saú. Brasil, 2013. [citado em 04 de novembro de 2016]. Disponível em: $<$ www.grupouninter.com.br/revistasaude/in dex.php/cadernosaudedesenvolvimento/.../ $01>$.

42. BRASIL. Ministério da Saúde. Instituto Nacional de Câncer José Alencar Gomes da Silva (INCA). Outubro Rosa 2016b. Vamos Falar sobre Câncer? Brasil, 2016. [citado em 04 de novembro de 2016]. Disponível em: $<$ http://www.inca.gov.br/outubrorosa/outubro-rosa.asp>.

43. BRASIL. Conselho Federal de Enfermagem. Sistema COFEN/Conselhos Regionais. RESOLUÇÃO COFEN № 381/2011. Normatiza a Execução, pelo Enfermeiro, da Coleta de Material para Colpocitologia Oncótica pelo Método de Papanicolaou. Brasil, 2011b. [citado em 26 
de novembro de 2015]. Disponível em: $<$ http://www.cofen.gov.br/resoluo-cofen-n3812011_7447.html>.

44. Smeltezer, SC; Bare, BG. Tratado de Enfermagem Médico Cirúrgica. 10 ed. Rio de Janeiro: Guanabara Koogan, 3v. 2006.

45. Melo, MCSC et al. O Enfermeiro na Prevenção do Câncer do Colo do Útero: o
Cotidiano da Atenção Primária. Rev. Brasil.Cancerol.. Brasil, 2012. [citado em 09 de outubro de 2016]. Disponível em: $<$ http://www1.inca.gov.br/rbc/n_58/v03/pdf/ 08_artigo_enfermeiro_prevencao_cancer colo_utero_cotidiano_atencao_primaria.pdf $>$.

\section{Como citar (Vancouver)}

Silveira BL, Maia RCB, Carvalho MFA. Câncer do colo do útero: papel do enfermeiro na estratégia e saúde da família. Rev Cient Fac Educ e Meio Ambiente [Internet]. 2018;9(1):348-372. DOI: http://dx.doi.org/10.31072/rcf.v9i1.517 